\title{
Politeness and Collective Identity: A Case Study of Two Endangered Languages of Arunachal Pradesh
}

\author{
Dimple Choudhury ${ }^{1}$ and Suranjana Barua ${ }^{1}$ \\ ${ }^{1}$ Department of Humanities and Social Sciences, Indian Institute of Information Technology Guwahati, Assam, \\ India \\ Correspondence: Suranjana Barua, Department of Humanities and Social Sciences, Indian Institute of Information \\ Technology Guwahati (IIITG), NH-37, Guwahati - 781015, Assam, India.
}

Received: February 21, 2021; Accepted: March 12, 2021; Online Published: March 20, 2021

This is a much revised version of a paper titled "Politeness and Collective Identity in Miju and Digaru: Two Endangered Language in Arunachal Pradesh" presented at the "National Conference on Revitalization of Indigenous Languages: Issues and Challenges', KIIT, Bhubaneswar, India in 2019.

\begin{abstract}
The study explores the phenomenon of politeness vis-à-vis collective identity in two indigenous languages of Arunachal Pradesh, India: Miju and Digaru. Through the differential use of discourse markers in various language settings, this paper examines politeness strategies used by the speakers of both languages to form inferences on the speakers' worldview and social knowledge of their respective communities in different contexts. The intrinsic structure of the language of a community and its lucid usage construes politeness together with a society's sociocultural principles. The socio-cultural characteristics fabricate the speakers' cognitive structure that formulates the phenomenon of politeness falling in with the language principles and boundaries. The current paper examines the production, projection and perception of politeness through discursive approach including inclusiveness/ exclusiveness strategies to understand natives' perspective on collective identity as speakers of endangered languages themselves. Further, the study takes linguistic politeness as a meta-pragmatic entity and tries to explore this phenomenon in the Miju and Digaru languages from the native's socio-cognitive understanding. In doing so, the paper appropriates Koller (2012), which, in introducing critical analytical parameters for analysing collective identity in discourse, talks about three levels of discourse - Macro-level, Meso-level, and Micro-level.
\end{abstract}

Keywords: politeness, language endangerment, critical discourse analysis, metapragmatics, collective identity

\section{Introduction}

The paper explores the phenomena of politeness in relation to collective identity in two languages of Arunachal Pradesh, India, viz., K'man or Miju, and Tawra or Digaru (Note 1), both of which belong to Mishmi language subgroup of Tibeto-Burman languages. Miju and Digaru are spoken in five districts of Arunachal Pradesh: Dibang Valley, Lower Dibang Valley, Lohit, Namsai and Anjaw. As per 2001 Census of India, there were about 17,257 Mishmi speakers in Arunachal Pradesh of which 17,013 dwelled in Lohit district itself. Further, according to 2001 Census of India and 2002 Census of China, there are only 6,700 Miju speakers in India and China; and only 9,332 Digaru speakers in India, China and Myanmar. Census of India 2011 has identified Mishmi as one of the languages not specified in the Eight Schedule and has further grouped the Mishmi subgroup under two categories: a) Mishmi b) others. The total population of the subgroup, noted by 2011 Census, is 44,100, of which Mishmi has 15,871 and others have 28,229 speakers. However, it has not shown the demographic breakdown within the Mishmis and others.

Though Northeast India is cherished for its linguistic diversity, the report of The UNESCO Atlas of the World's Languages in Danger 2010 reveals a startling aspect: Arunachal Pradesh alone has 30 endangered languages that are on the verge of extinction and Miju is listed as one of the vulnerable languages (Baruah, 2015). Blench (2017, p. 1) claims both Miju and Digaru as highly endangered and claims that the threat for this endangerment is Hindi but current UNESCO Atlas of the World's Languages in Danger report has removed Digaru from endangered language list and has upgraded the status of Miju from endangered to 'vulnerable'. Blench, however, states in his evaluation of the language situation in Arunachal Pradesh that the UNESCO report on language speakers is estimated from census data and this estimate is not based on the level of competence of speakers: a competent 
mother tongue speaker vs. a non-competent mother tongue speaker (Blench, 2018). Accordingly, the current study considers the issue of the threat to both languages from the perspective of identity and the factor of politeness within a Discourse Analysis approach as outlined in the sections below.

\section{Collective Identity, Politeness and Endangered Languages}

Every language carries inimitable linguistic features implying a unique worldview and knowledge: its extinction can lead to lose such assets together with the language. Both Errington (2003) and Kroskrity (2000) confirm that language is an eminent property of identity. To conceptualize identity, it is necessary to comprehend the types of identities one associates with. Snow (2001) forwards three types of identities in his work on collective identity and expressive forms: personal, social and collective. He links personal identities to qualities and properties of oneself by oneself, social identities to the effort of an individual to incorporate themselves in a social arena and collective identity to the sense of 'one-ness' or 'we-ness'. However, Snow (2001) specifies the flexibility of collective identity as a concept and notes that the shared sense of 'one-ness/we-ness' not only drives the cognitive and emotional being of an individual, but also one's morality periodically. In this regard, Snow has forwarded Melucci (1989) and Polletta and Jasper (2001)'s claim on collective identities as highly complex and multi-dimensional, even in a specific role, in reference to the emotional, cognitive and moral aspects (Snow, 2001). The presence of such dimensions is likely to create a powerful sense of collective identity. Snow draws on the importance of these dimensions in collective identity:

"Clearly, a collective identity in which the boundaries the boundaries between "us" and "them" are unambiguously drawn, in which there is strong feeling about those differences, and in which there is a sense of moral virtue associated with both the perceptions and feelings, should be a more potent collective identity than one in which either the emotional or moral dimensions are weakly developed." (Snow, 2001, p.10).

Among members of a group, there is thus a moral obligation to respect the boundaries across various levels of social structure. Kádár and Márquez-Reiter (2015) claimed that this responsibility is presented in social practices such as by following the norms of interactions/conversations, etc. The phenomenon of politeness intertwines with morality in such social norms/expectations as both have an important role in social indexing. Though the evaluation of these norms and expectations is a common feature in social organization, it differs from language to language or society to society. It is necessary to note that the importance of politeness markers not only contributes for evaluating a speaker's adherence to social norms which thereby frames one's personal/ collective identity, but also that a gesture of politeness in discourse protects self-imagel face of both the speaker and hearer which further restores ones' identity/collective identity in line with Goffman's face theory (1955) which states that 'face' is the positive public image one seeks to project in social interactions.

\subsection{Elements of Identity and Politeness in Minority languages}

The functional distribution of speech, language maintenances, language shift, limitation, delimitation and even interaction of speech communities are attached to a speaker's perspective on identity. The viewpoint of indigenous people on their identity proclaims their attitude and ideology towards their mother tongue. Baker says in this regard:

“...in the life of a language, attitudes to that language appear to be important in language restoration, preservation, decay or death" (Baker, 1992, p. 9).

Language attitude towards mother tongue is largely expressed through how speakers acquire, use and maintain the language. These important aspects of language attitude are very important for studies related to language endangerment and death and, ultimately, in the process of understanding production, projection and perception of speaker's identity. Researches on identity construction are grounded in the view of language as discourse, that is, 'actual instances of communication in the medium of language' (Johnstone, 2002, p. 2). As speakers' identity reflects in their discourse, their attitude towards their language or selection of discourse, simultaneously, speak of their preference while building a collective identity. Language is the most obvious means through which social order, hierarchy and power is exercised and this predicts the interconnectedness of language and dominance (Fairclough, 1989). With the emergence of language ecology as an independent area of study, this interconnectedness of language and dominance started receiving greater attention. Wendel and Heinrich (2012), in this context, has described language ecology from two different contexts: stable vs competitive. According to them, communities in stable ecologies, do not have any power over another, either in economy or in technology, and it has regulated an equal position for all the languages spoken in a language environment. Competitive ecologies, on the other hand, are exceptionally stratified and due to this stratification of social organization the status of languages spoken in a social structure too gets affected (Wendel and Heinrich, 2012). Wendel and Heinrich (2012) has added that this power driven social structure results in declination of minority languages 
through the dominant languages overpowering them. And thus, for sustainability and stability, minority languages should make their best effort to project a positive collective identity in a competitive language environment.

The current study is a preliminary investigation into politeness and collective identity in a competitive ecology as exemplified in Lohit district of Arunachal Pradesh. Most of the mother tongues spoken in Lohit are minority languages, and Miju and Digaru, by virtue of having the highest population among these minority language speakers (Census of India 2011), might presumably enjoy a relatively stable ecology in Lohit valley which has more than eighteen other mother tongues (see discussion below in Section 4). However, the increasing role of Hindi as a lingua franca in these communities and the establishing of English as the official language has far reaching implications for these communities including the creation of a competitive ecology which has endangered minority languages. Rondo (2016) reports a case study in which it was found that:

“...90 percent of the parents do not teach their children in the mother tongue especially in the urban areas of Roing and Tezu towns. People of the younger generation prefer to speak and conversing in Hindi and English or other third languages. It is very unfortunate that about 50 percent of the elderly people of the society are not comfortable in their mother tongue particularly in urban dwellings" (Rondo, 2016, p. 4).

The above quotation hints at socio-cognitive reasons for endangerment in which sociological variables like age and urban/ rural backgrounds have bearings on how language is used in a community. The overpowering use of Hindi / English by Miju and Digaru speakers is likely to be featured in the collective identity that each speaker attempts to construct. One of the aims of this paper is to explore what alternate discursive options are being promoted by these dominant languages that may be causing change in patterns of usage in such competitive ecologies.

\section{Theoretical Approach and Methodology}

As outlined above, this paper seeks to examine the phenomena of politeness in the context of collective identity of Miju and Digaru as speakers of minority languages particularly in the Lohit district. Theorists like Sara Mills, Jodie Clark, Jonathan Culpeper, and Louise Mullany in Linguistic Politeness Research Group (2011) have defined politeness as a social index that secures self-identity/collective identity by enforcing moral compulsion to respect the boundaries of social structure. Mills says:

"I use politeness to refer to behaviour which I see as showing concern for others and which fits in with, and shows respect for, wider social norms" (Mills, 2011, p. 2; italics added).

She adds that the phenomenon of politeness exhibits discursive feature as it lays out language choices to communicators, adhering to the norms of social structure and thereby build up in-group and out-group (Note 2) criterion. Considering these aspects of discursive approach, this paper aims to understand the cognitive perspective of Miju and Digaru on polite discourse makers and its relation to their collective identity as distinct language communities. In particular, the current study has applied Critical Discourse Analysis (CDA) with a socio-cognitive approach for analysing discursive incorporation of collective identity of the speakers of both the languages.

Theorists like Fairclough and Wodak (1997), Fairclough (2003), van Dijk (2008), Wodak (2002), have spoken on different frameworks adopted in CDA. van Dijk (1993) has emphasized the importance of incorporating cognitive theories with linguistic and social theories in CDA noting that 'Critical discourse analysis can only make a significant and specific contribution to critical social or political analyses if it is able to provide an account of the role of language, language use, discourse or communicative events in the (re)production of dominance and inequality' (van Dijk, 1993, p. 280). Fairclough (2013) describes CDA as contributor of critical social analysis focusing discourse while analysing the relation between discourse and other social elements (power relations, ideologies, institutions, social identities, and so forth). Wodak (2002) has recognised the significance of aspects, such as, ideology, power, hierarchy, gender and sociological variables to interpret a text (Weiss and Wodak, Eds. 2007). According to van Dijk, CDA is not a method but a perspective or approach to study aspects that are related to society and politics through discourse. He adds that a society can be interpreted through discourse by exploring the mental model of the speakers testing the mentioned sources. Furthermore, van Dijk (2014) states about the impact of one's ideology in the formation of mental model. Koller (2012) notes regarding the discourse as social practice:

"In discourse as a social practice, socio-cognitive representations that a text producer holds about a social group, be it their own or another, translate into the textual construction of a collective identity for it" (Koller, 2012, p. 20). 
Considering socio-cognitive representation as a mixture of beliefs and knowledge, norms and values with emotions, Koller refers Kunda (1999) with a view to stereotyping the membership of the group/community in line with the behaviour of the members. She, further, clarifies that socio-cognitive representation does not reflect the mental model of individual person, but of a particular community or group, shaped in the process of socializing and communicating among the members of the group. Koller, in her framework for analysing collective identity, has introduced three parameters of analysis in CDA - Macro-level (social context), Meso-level (discourse practice context, such as, production, distribution, reception, appropriation) and Micro-level (text). Of these, Macro-level is the socio-cultural and socio-economic factors that shapes the underlying mental model for a speaker's discourse: acceptability, validity, appropriateness and so on. In this level, linguistic and discursive tools are to be used connecting them to broader social and cognitive influences as collective evidence. The Meso level is intended to respond to questions about the production, delivery, reception and appropriation of text. Koller, therefore, suggests that this level of research should be undertaken to examine the roles and relationships involved in discursive practice, while keeping in mind the formation of connections between the results of this level and the previous one. The socio-cognitive representation of a group/community, here, allows to inference stereotypes as well as implicating the ideal type to be a member, featuring norms and values of that group/community. Such desirability criterion motivates the members or speakers to attain what is believed to be good, positive and desirable in the group/community. The Micro level serves as the most concrete and salient manifestation of discourse in the linguistic study of text. It can therefore be attributed primarily to being 'descriptive' of the data available (Koller, 2014, p. 154-155). Text is considered as the in-depth level of analysis through which members of groups/communities transmit their collective identity: tendency of adaption and consistency of linguistic features across the text/discourse. In fact, the coherence and interpretability of discourse relies on the transparency of a speaker's mental model and can be derived from three sources: text, meaning and inference (van Dijk, 1993, 2003, 2009a, 2009b, 2014).

Drawing on the concept of collective identity of Koller (2012) as a socio-cognitive representation of the members of a community, this paper attempts to examine notions of collective identity among the Miju and Digaru speakers, which is constructed, negotiated and changed through discourse within a community and may differ between communities. Appropriating the three levels of CDA to study the formation and projection of collective identity, the paper has included mock speech, conversation data and a few elicited data for analysis of politeness. Limited research has been done till date on the phenomenon of politeness factor in Tibeto-Burman languages and among them are Betholia (2005) and Boro (2012). Betholia (2005) illustrates politeness markers like - bi $\sim p i$, - ča $\sim j a$ and $-s i$ are used in Meiteilon as politeness markers which indicate power and hierarchical relationships. Boro (2012, p. 83-108), in his study on serialized verbs in Bodo has extended examples of politeness marker -nai used in imperative sentences, such as, aik ${ }^{h} u$ lin hor-nai whose literal meaning is 'call your mother (by shouting from here)'and aik $u$ liy-nai that means 'call mother'. Bodo speakers also use markers like -bra, -lwi and -na in imperative construction which provide an interpretation of politeness. Languages like Bodo and Meiteilon indicate that the phenomenon of politeness is featured in Tibeto-Burman languages of Northeast India in different degrees and context. This paper will extend the study of politeness research in the Miju and Digaru languages to understand speakers' evaluation for their collective identity as speakers of minority languages.

\section{Politeness and Collective Identity: A Case for Miju and Digaru}

The main aim of politeness is to create and maintain an environment so that people can project a positive face or identity of themselves and associated community (Brown and Levinson 1987). With the acceleration of globalization, we no longer live in a mono-cultural society and this has induced the need of practicing polite expressions with varieties of techniques and degrees to maintain a smooth and harmonize communication in a multi-cultural society. Correspondingly, discursive theorists like Mills (2009), Terkourafi (2001) and Arundale (2010) highlight politeness as a social index. As the concept of politeness, in production and perception, varies from culture to culture and language to language, Miju and Digaru too presumably hold and display the concept discursively and socially.

Arunachal Pradesh, where the Miju and Digaru population is concentrated, is a multilingual state and has the asset of twelve independent subgroups of Tibeto-Burman (Post and Burling, 2017). On account of this overwhelming variation, Hindi is used as a lingua franca across Arunachal. Census of India (2011) reports Lohit district is a region with eighteen mother tongues with total population of 145,726 - Nepali (22,200 speakers), Mishmi (Idu, Miju and Digaru) (17,013), Assamese (16,320), Hindi (8,286), Bengali (7,425), Miri/Mishing (6,707), Chakma $(5,381)$ and others. Aside from that, the official language of Arunachal is English. English is the only medium of instruction available in educational institutions in Lohit and it is also extremely pertinent that school education is not available to speakers of these languages in their mother tongues - the implication of this was explored in 
Choudhury (2020). In addition, English is used in Lohit district's government offices and public sectors. Thus, native speakers of both Miju and Digaru use Hindi and English (primarily Hindi for conversation) regularly in daily life. Dey (2016) has reported on the overwhelming usage of Hindi as the language of communication:

"The younger generations, once they go out of their home domain, do not speak in their native tongue and prefer to communicate in Hindi even among themselves. In Arunachal Pradesh, Hindi or the so-called Arunachali Hindi serves as the link language among different other language groups of the State.” (Dey, 2016, p. 32)

Baruah notes that "all the language communities of Arunachal Pradesh are threatened by Hindi language" (Baruah, 2015, p. 75). Within such a competitive language ecology (Wendel and Heinrich (2012), it is important to ask what impact the wide usage of Hindi and English have on the discourse of the native speakers and which of these features may indicate rapid decline in native language patterns. To have an insight into these issues, it is very important to know about the society of the speakers, their social practices and language practices prevalent in the society. This is what justifies the use of Koller's three parameter analysis which uncover the social and cultural positioning of the mentioned indigenous people. This discursive analytical approach accumulates aspects such as linguistic structure, along with underlying social and cognitive influences and this paper will analyse whether a language losing its social status is connected to limited cognitive sources leading to endangerment and will also to identify if there are any differences in communication strategies between the two language varieties thereby confirming their differences. In other words, the critical research questions to be asked are: i) how do Miju and Digaru encode social (macro-level) features with a consideration for meso-level relationships of and between speakers ii) What do these features reveal about the discourse strategies (micro-level features) available in the respective languages and how do they measure up against alternatives in the dominant languages of communication? While trying to link these to their status as minority languages - existing patterns of language use would hopefully reveal identity patterns of their speakers.

\section{Critical Discourse Analysis of Miju and Digaru}

\subsection{Discourse Analysis on Social Context: The Case of Miju and Digaru in Arunachal Pradesh}

It is a linguistic platitude that while adopting Hindi and English, a Miju or Digaru speaker would also adopt the basic positive conversation strategies of these languages and thus some basic words that signify the attitude of politeness and its use. In English, words like hello, please, thank you, sorry, excuse me, welcome and so on are routinely used as positive politeness strategies that express concern for others. Similarly, Hindi has words like kripya 'please', dhanyavad 'thank you', namaste 'hello', swagatam 'welcome' etc. However, these expressions are not universal. Miju and Digaru do not have parallel words or expressions indicating these notions. Digaru uses the formulaic expression / pra je/ 'Are you good?' for greeting people when the situation demands. Miju too does not have notions like thank you and sorry. /hatai hamat mai/ and /hatai kasit mai/ are expressions of gratitude in Miju which means 'feel very happy (/hamat/)/good (/kasit/)' in a polite conversation.

As seen from the discussion above, the manner in which the concept of politeness is projected and viewed differs from language to language. Miju and Digaru also seem to present this phenomenon using different politeness strategies of words/expressions. But then when a speaker begins to understand the relationship of language usage and positive image in a society while learning a foreign language, he/she attempts to maintain it efficiently according to the context. So, it is likely for a speaker to bring a new concept into his/her language and use it in accordance with language situations, though his/her mother tongue does not allow doing so. Sánchez's (2003) study on Quechua as L1 and Spanish as L2 acquired by Quechua speakers identifies that both the languages have brought considerable changes in both L1 (Quechua) and L2 (Spanish) speeches of the speakers. She illustrates the changes in L1 (Quechua) for L2 (Spanish) influence, which includes -

"absence of obligatory accusative marking on direct objects; emergence of indefinite determiners in a language with no determiners; and a higher frequency of post-verbal objects in an SOV language" (Sánchez, 2003, p. 6-7).

Sánchez has forwarded a functional hypothesis to label these changes which suggests that bilingual speakers can activate a linguistic feature in language A for the influence of language B or vice versa when L1 and L2 do not share it. This type of changes, according to the hypothesis, may appear as a new linguistic feature or as synthesis of both languages in bilingual speakers (Sánchez, 2003, p. 11-15). It may be surmised with regard to politeness that, when a non-native speaker learns the word 'thank you' in English, he /she also starts to nativize and reappropriate it in the discourse of his/her mother tongue, as per context, if his/her mother tongue does not hold words/expression similar to that. This paper therefore contends, firstly, cognitive awareness of limitedness in the speaker's mother tongue can promote code mixing and gradually code switching according to the demand of 
language situations. Secondly, this awareness of limitedness may induce a sense of insecurity or inferiority in the minds of speakers which may encourage gradual language shifting as is happening in Arunachal Pradesh. In a similar context, Adegbija (2001) talks about intergenerational transmission in language use and language attitude among Oko speakers, an endangered Kwa language spoken in Africa. Oko speakers have shifted to English for their attitude of inferiority towards their mother tongue as Oko is considered as unworthy in official context.

The current paper examines collective identities of Miju and Digaru in the context of politeness strategies that are available in the languages. It also will seek the comparative preference for other discursive elements made available by Hindi/ English to the speakers. Through this, hopefully, a different insight into language endangerment would be possible: one that addresses the cognitive awareness of Miju and Digaru speakers regarding the limitedness of their mother tongue to maintain a positive collective identity which is surmised here, and other that seek the tendency of provoking a sense of insecurity and inferiority towards mother tongue and thus lead to language endangerment. The data presented is part of preliminary field survey by the first author for studying these endangered languages. The data used for this paper was collected from three Digaru speakers and three Miju speakers (Male speakers: three Digaru; Female speakers: three Miju) belonging to two age groups - 20 to 25 and 35-40. The mentioned age group is chosen to check the speakers' difference of language use and politeness strategies and present their attached cognitive attitude in the context of age variation. The data was recorded using Sony ICD-UX560F/S Recorder and samples reported here was analysed using standard Discourse Analysis notation which are given in the List of Symbols.

\subsection{Text Analysis: Miju and Digaru}

In this section, to look into the concept of politeness and the constructed collective identity, considering the factor of language endangerment in Miju and Digaru, conversation speech data are included for Critical Discourse Analysis. Speech data of similar pattern are taken, for both the studied languages, to draw a comparison between the two and bring out differences in politeness strategies, if any. Bringing forth Koller's second parameter - meso level of CDA, data included for the analysis of both the languages are - a) a mock speech addressed by a 'teacher' to 'students' and 'audience', b) a mock conversation between two respondents (as per given situation and role), c) imperative sentences (directly elicited). As the parameter suggests on the genre of the text with a focus on the roles of the interlocutors, the data chosen for the study includes mock samples of formal speech of a teacher to students and other audience present with the response being prepared in advance; conversation between two 'strangers', conversation between a 'hotel manager' and a 'customer' to note the use of politeness markers in each discourse context assigning different roles to the speakers and directly elicited speech samples.

In the first extract below which presents Miju speech data, the respondent who is a teacher by profession is requested to give a mock speech addressing her imagined students and other audience on the occasion of a school function in the presence of the principal. The respondent is a Miju female teacher of age group 35-40.

\section{Extract I (Miju)}

\section{[Miju_F01_200718]}

((The context is a mock speech in the presence of two members: the first author interviewer and interviewee. Interviewee is female Miju speaker of age 35 and the cited text occurs when the speaker was requested to give a mock speech imitating her role as a teacher at a vote of thanks. The speaker prepared a speech and then read it out during the recording imagining the formal social situation of a school function.))
1) $>$ tonit
Tenual
de fayfon
Thi $\downarrow h u$ tsale
$h i<($.)
2) $>$ kin
annual
day function
COMP here come
COMP
$1 \mathrm{PL}$
hatai hamat
mai<. (0.6)
very
happy
feel

'We are very happy that you have come to our annual function day'.

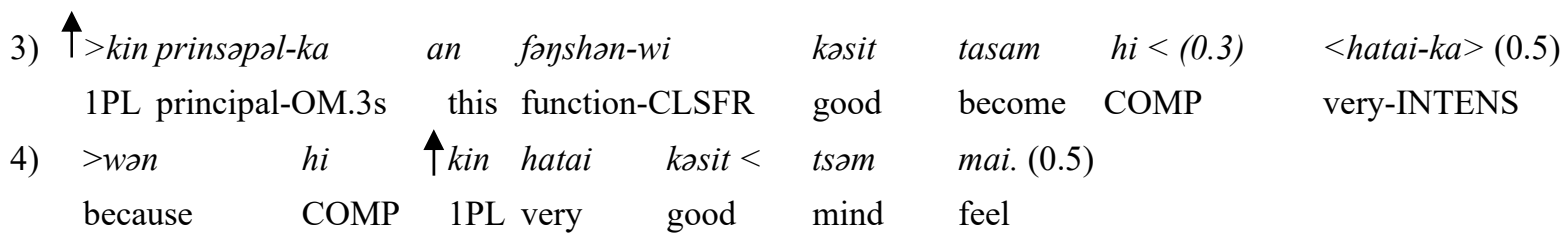

'We are thankful to our principal for making the function good (helping to organize better) and that is why we are 
feeling good.'

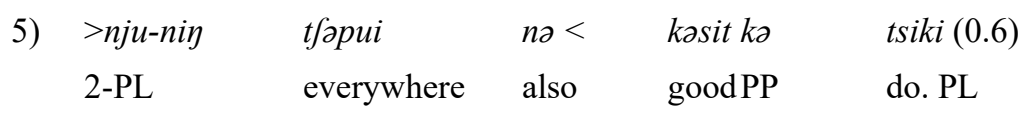

'You all have performed well everywhere'.

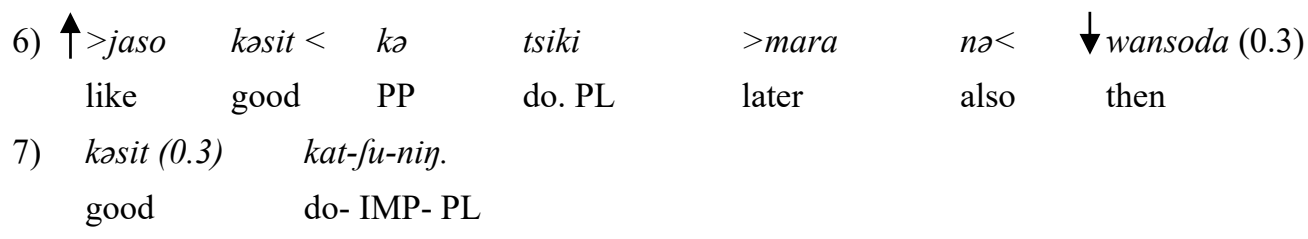

'Your performance was good now/today and a similar performance is expected later'.

Extract I discloses three definite positions in the concept of politeness and constructive identity. First, the speaker in her turn (quoted in line 2) uses the inclusive pronominal 'kin' to include the imaginary principal and all present for her speech. Given that this was a mock speech, her use of the inclusive first person plural pronominal from a speech that she had prepared in advance is important - it indicates a certain social realization or obligation (macrolevel) that leaving out the others from the ambit of action may be considered impolite as she has the 'privilege' of speaking. Through this politeness strategy of using the we-pronominal ("we-ness" in the sense of Snow, 2001) and expressing a "concern for others" in the sense of Mills (2011) cited earlier, the speaker not only includes the principal and others (imagined context) but also perhaps uses inclusiveness with the consciousness of the interviewer's presence in the speech situation (a socio-cognitive context). Her deliberate use of the first person singular usage may be deemed impolite and the inclusive plural pronominal continues in line 4 to evoke a positive identity incorporating politeness factor - as 'we' are grateful to the principal for his help and 'we' are happy about the function going well. Also, in line 5, it is notable to see the stress of including each and every participant by using the plural marker, i.e, /-niy/ with second person to mean 'you all' to acknowledge each and everyone's effort in the function and thereby confirming/expecting similar support/effort in later days (line 6).

Thus, Extract I clearly states the importance of inclusive plural pronouns to acknowledge the identity of the audience and the principal as an active contributor in her imagined sense and the interviewer in the real context while evoking the sense of politeness. Second, the speaker has not used any specific word/term for gratitude in the Extract, rather she has used standard formulaic expressions like /hatai hamat mai/ which literally means 'feeling very happy' denoting we are very happy to see you here (line 2) and /hatai kasit tsam mai/ (line 4) 'feel very good' to the audience and principal respectively, integrating the politeness remark of gratitude. Moreover, the speaker has used 1PL inclusive to express happiness, specifying that her acknowledgment is not a personal subject but a shared feature of the "organising committee". The speaker's attempt to emphasize this incorporation also represents as a marker of politeness via use of inclusive participles in the mentioned context. This not only indicates socio-cognitive obligation of speaker to add listener in context to maintain a moral aspect of inclusiveness but also reiterates Goffman's face theory (1955) and Snow (2001)'s concept of positive collective identity, exercising both strategic and social indexing behaviours. That is, the speaker wishes to maintain a positive face (Goffman, 1955) while also invoking a collective identity. Third, apart from these politeness indicative discourse markers, another aspect to be noted in Extract I is the code-mixing. The speaker has code mixed the English term function in her speech. As Miju speakers use the word /phru/ to mean 'arranged meeting', her use of the English alternative in her pre-prepared speech that she read out could imply both a sense of inadequacy regarding her native tongue option and her understanding that the English variant would be a more appropriate option give the formal (Koller 2012 meso-level) role of teacher in school environment where English is the medium of Instruction. The reason for choosing a foreign word over a native variant in spite of availability of a native word explains that the use of 'function' may thus be related a macro level awareness of formalness since the respondent was asked to use the mother tongue throughout the speech.

Besides, when the speaker was later asked on her perspective on the speech she delivered, she informed that she was not confident in the degree of its formalness as a public speech, which triggers a formal context. She added that the degree of formalness would have been more if she would have delivered her mock speech in English. She further explained that Miju does not have politeness markers like 'welcome', 'please', 'sorry' for which they usually code mix English for such terms when situation demands. (Note 3)

As the study has considered different types of discourses for analysis, the next speech data is extracted from a different interview with two native Miju speakers performing role-playing conversation. In the role play, the 
respondents were asked to have a real time conversation enacting as a 'hotel manager' and a 'customer'. The participants of this interview are two female speakers' acquaintances belonging to age group 35-40 and unlike the prepared speech in Extract I, the following extract is an example of spontaneous speech via role play.

\section{Extract II (Miju)}

[Miju_F02/F03_180718]

((The context is a mock interview in the presence of three members: first author/ interviewer and two interviewees. The interviewees are two female Miju speakers of age group between 35-40 years and the cited text occurs when the speakers were requested to present a mock conversation imitating a 'hotel manager' and a 'customer'.))

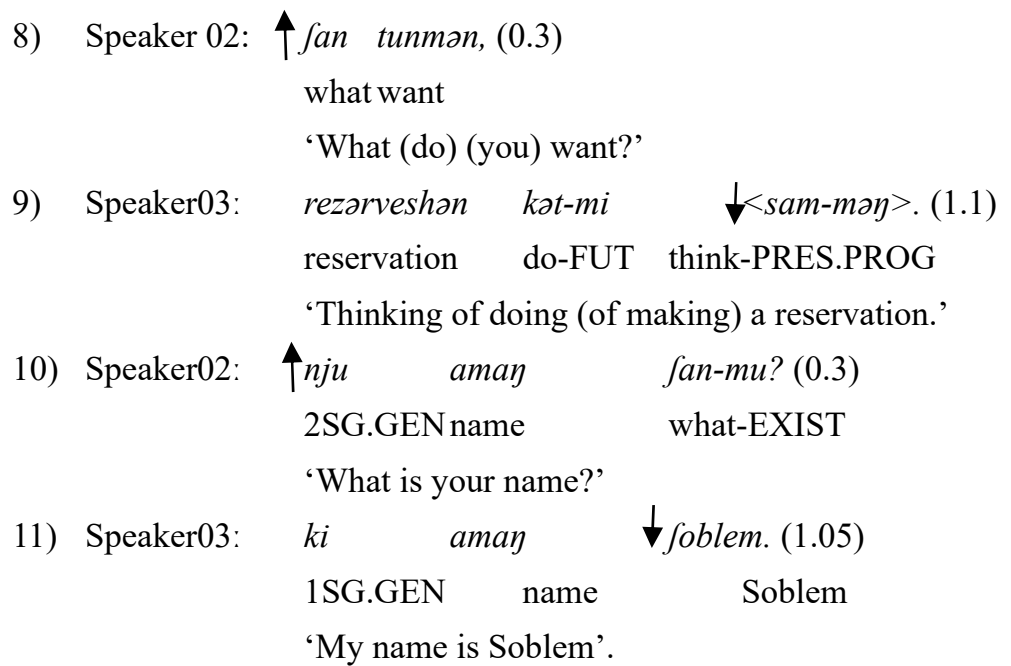

In Extract II, the conversation data pertinently does not show any overt standard politeness markers or initial greetings. In the introductory sentence (line 8) of the conversation, the speaker has directly addressed the desire or need to the hearer without any proper introduction. Moreover, the conversation does not carry any word or expression invoking politeness which, otherwise, is normally perceived in the speech of a native English speaker or a native Hindi speaker, given the context of interaction between two strangers/ unfamiliar persons. To interpret the reason behind the absence of overt politeness feature in a conversation (where one expects conventional politeness features), the two speakers were asked about their perspective of politeness used in the discourse of their conversation. They were requested to assign a degree denoting the level of politeness for their conversation and for that, speakers were asked to choose among the five given degrees, i.e, very polite, polite, not polite, rude or none of the above. Both the speakers opted for none of the above. They justified their choice saying that people are treated equally in their language community. (Note 4) According to them, they do not have the concept of superior or inferior and it is normal to have a conversation without using any definite polite expression, irrespective to status, gender or age. This may imply that there is a less pressure to save face and establish collective identity on both the participants while having the conversation: on the other hand, it is surmised here, this also might imply non-usage of standard greeting strategies in imagined and spontaneous social contexts might be indicative of declining native language usage in social settings in the public domain.

Thus from the above two extracts in Miju, it is clear that inclusive particles and standard phraseology are used in prepared speech whereas in spontaneous speech, the instances of standard greetings are non-existent possibly due to cultural constraints as enumerated above. Barua (forth/2021) provides an in-depth account of such culturally varied strategies of politeness in different languages.

In the following extracts III and IV, similar contexts of speech - prepared speech as in I and spontaneous role play as in II - were provided to Digaru speakers. The data reported in Extract III is collected from a Digaru speaker (male teacher) of age group 20-25. Similar to Extract I, the interviewee presents a mock speech addressing the students on the occasion of an imagined annual school function.

\section{Extract III (Digaru)}

[Digaru_M04_220718]

((The context is a mock interview in the presence of two members: the first author interviewer and interviewee. The interviewee is a male Digaru speaker of age group between 20-25 years and the cited text occurs when the 
speaker was requested to present a mock speech imitating a teacher at a vote of thanks. The speaker prepared a speech and then read it out during the recording imagining the formal social situation of a school function.))

\begin{tabular}{|c|c|c|c|c|}
\hline $\begin{array}{l}>\text { tahiy } \\
\text { today }\end{array}$ & $\begin{array}{l}\text { tjay } \\
\text { very }\end{array}$ & $\begin{array}{l}\text { pra } \\
\text { good }\end{array}$ & $\begin{array}{l}\text { aljosi-a } \\
\text { appy- INCL.PART }\end{array}$ & \\
\hline aneh & weh & äyshən & $n \quad h a n a-j a$ & kanum $<$. (0.8) \\
\hline
\end{tabular}

'Today we are very happy because you have come to this annual function'.
14) >prinsipal fo weh program habray-ja kanum $<-$ principal sir DET program help-PST because

'Because principal Sir helped in this program'.
15) tjay haljosi-a (.)
aa-lay fayshan ke
hana-ja $\uparrow$ kanum, (.)
very happy-INCL.PART
child-PL function PP
come- PST
cause

'We are very happy because children came to the function'.
16) aneh
$m e-h i$
tjay
pra
$z i-j a$
tahip, (0.6)
$2 \mathrm{PL}$
person-QUAN very
good
work-PST today

'You all worked well today'.
17) $<$ aneh
pra-m weh
weh riy-ja >
ha aa amay
tfo-je-m
kanum.
2PL good-NEG
be-INFIN
1SG child name
keep-PST-NEG
cause

'You all do not feel bad(mind) because I removed child's name'.

Extract III illustrates two different aspects of politeness with the use of $-\mathrm{a}$ ) inclusive particle a- in lines 12 and 15 and b) expressions indicating politeness (line 12 and 15). Line 12 has the inclusive particle /-a/ to include all imaginary organizers and viewers once again keeping intact the moral aspect in the inclusiveness for a formal public affair (as done in Extract I) as practical demonstration of Goffman's face theory (1955) and Snow (2001)'s concept of positive collective identity. Line 15 repeats with the same inclusive particle to express the happiness of everyone rather than of the speaker alone. Similarly, in line16, the speaker has stressed on the inclusion of all the participants while acknowledging their good performance with the pronominal /aneh meh-hi/ 'you all'. Here the speaker has included the aspect of politeness by constructing an identity of a 'good performer' for the participants. However, in line 17, the speaker has completely taken the responsibility of removing the name of few students using the 1SG statement instead of 1PL (inclusive statement), though the function is not a personal affair. This indicates a compliance to negative face theory (Note 5) of Brown and Levinson (1987) whereby the teacher is taking the responsibility of the act. In the mentioned line, the expression / pram weh rig-ja/ 'do not think bad/ do not mind' is used to maintain a moral order for the action of the teacher. This shows that the speaker is aware of the importance of accepting his flaw in front of his students, but, since Digaru does not have overt words to convey the message of apology, he has used the mentioned periphrastic expression instead. Also, in line 12) and 15), the speaker has used the expression /haljosi-a/ 'happy' not only to mean the emotion of happiness but also to express a series of positive related emotions or attitude such as thankful, blessed, overwhelmed etc. of English language. In Digaru the denotation /haljosi/ can signify such emotions or attitude.

Similar to Extract II conversation speech data, two Digaru male speakers of the age group 20-25 were also instructed to play the role of a host and a visitor meeting for the first time in a home environment. In contrast to Extract II where the speakers were mere acquaintances, the speakers whose discourse is reported in Extract IV were friends which might explain their initial greeting and also code-mixing. Also, in contrast to Extract II speakers who were both females of 35-40 age group, these respondents were both males in the younger age group of 20-25.

\section{Extract IV (Digaru)}

[Digaru_M05/M06_220718]

((The context is a mock interview in the presence of three members: first author interviewer and two interviewees. The interviewees are male Digaru speakers of age group between 20-25 years and the cited text occurs when the speakers were requested to present a mock conversation imitating the role of a 'host' and a 'visitor'))
18) Speaker05:
hai (0.4)
个ha amay
afilu. (0.5) 
hi(English) 1SG name ashilu

'Hi. My name is Ashilu'.

19) Speaker06:

$\begin{array}{lrl}\text { hai (0.9) } & \text { 个>njuamay } & \text { ja-mlay }<\text { (.) } \\ \text { Hi(English). } & \text { 2SG name } & \text { what-IP }\end{array}$

'Hi. what is your name?'

20) Speaker05:

$\downarrow$ afilu. (.)

ashilu

'Ashilu'.

21) Speaker06:

$$
\begin{gathered}
\text { 个<atsa }>(0.5) \\
\text { okay(Hindi) } \\
\text { 'Okay'. }
\end{gathered}
$$

(...) ((few lines are deleted as they do not provide any substantial input in the analysis))

22) Speaker05: ha matfei in-ge

1SG water little-ADV SUFF

$\downarrow$ hayza-na (1.5)
give-IMP

'Give me some water'.

23) Speaker06

nju matfei $\boldsymbol{\uparrow}^{\text {h }}$ e timdi-je? (0.4)

2SG water cold drink-INT

'Do you drink cold water?'

24) Speaker05:

\section{$\downarrow$ am.}

yes

'Yes.'

The speakers construct different degrees of politeness as well as identity in Extract IV with code mixing and imperative construction (line 18, 19 and 22). Firstly, the speakers have code-mixed both Hindi and English with Digaru to have an effective communication expected in an initial greeting. Here, English word like $h i$ is used as an overt politeness code to maintain a positive face among the speakers. Goffman (1955) while talking about face and social relationship mentions that the ritual of greetings and farewell in a conversation encounter helps to maintain a good will among the interlocutors and at the same time prevents disruption in their relationships.

Secondly, even the imperative construction/-na/ (line 22) has the possibility of indicating a degree of inclusiveness with hortative modality in the above conversation for two different reasons - 1) As Digaru speakers have adopted Hindi as L2 and the given conversation shows the use of Hindi word in (line 21:atfa), it is possible that the speaker maintains a code mixed hortative (like chalo na in Hindi which means 'Please let us go') to imply a certain affability in that context. Here, the discourse is once again revealing aspects of macro-level collective identity in micro-level text with consideration for the meso-level concerns of cordial relationships (in the sense of Koller 2012). The initial code-mixed 'Hi' (lines 18-19) as form of greeting and an inclusive particle with hortative function even in an imperative sentence (line 22) imply a sociality and hence collective identity in the situation of role-play. Unlike Extract II which was deemed egalitarian with no politeness markers necessary amongst the older speakers engaged in role-play, the affability of -na makes for a politeness marker amongst younger speakers thereby invoking collective identity. Furthermore, from the given Extracts I-IV, it is noted that not only Digaru but also Miju have distinct markers in imperative sentences. In Extract I, the speaker has used the (imperative/hortative) marker /-su/, while asking for a good performance (line 4) as in Extract IV: line 22) marker /-na/ while asking for a glass of water.

The above findings contrasting prepared formal speech with spontaneous role-playing contexts are represented in the chart below for greater clarity: 


\section{Analysis of Politeness Phenomena: Pronoun/Particles and Standard Greeting Form}

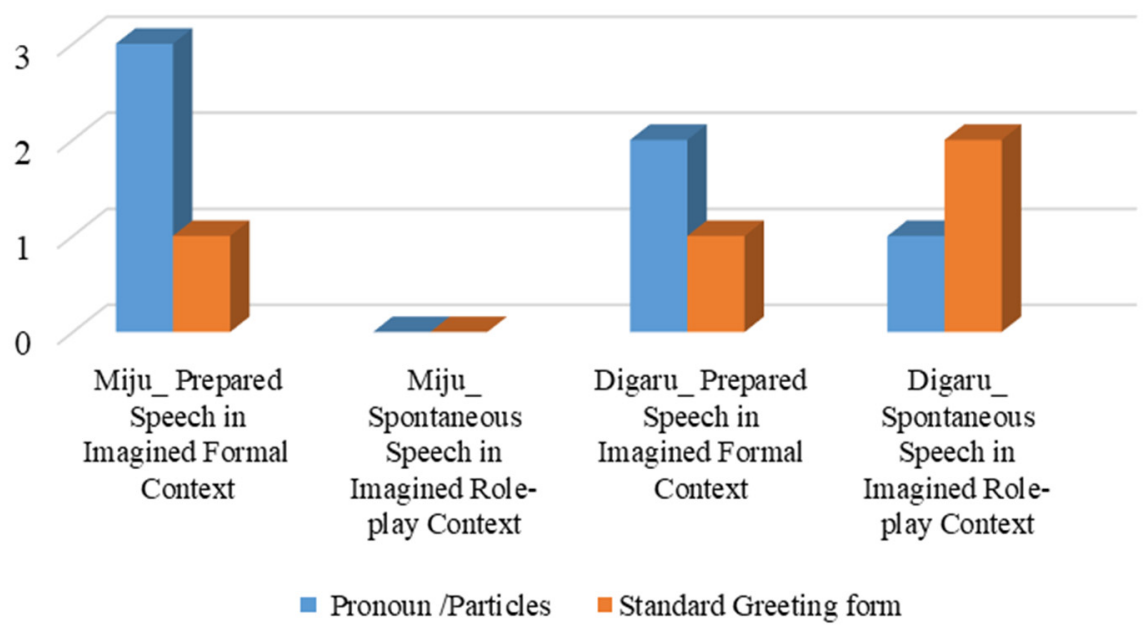

Figure 1. Instances of inclusive pronominals/ particles and standard greeting forms in different contexts

\subsection{Elicited Imperative Constructions in Miju and Digaru}

In order to examine the projection of politeness via inclusiveness in the action being implied, different types of sentences constructions (with imperatives/ requests etc) were elicited from speakers of both Miju and Digaru in their native languages to reconfirm their patterns of usage. The elicitation was done using both English and Hindi and some of the samples are reported below to show how hortatives may function even in imperative markers to show affability as a type of collective identity invocation.

\section{Digaru}

25) ha phalam wiy-ge hay-na o

$1 \mathrm{SG}$ tea little-ADV SUFF give-IMP POL.MAR.HORT

'(Please) Give me some tea'.

26) indo

more drink-IMP POL.MAR.HORT

'Drink more'.

27) tabrema tana manjo hay-na

meat and curry

cook give-IMP

'Cook meat and curry'.

28) taph $^{h} r$

$$
\text { kate-ja }
$$$$
\text { bo-na }
$$

river

swim

$$
\text { go-IMP }
$$

'Go to swim in the river'.

29) tap ${ }^{h} r a$

$$
\text { kate-ja }
$$

bo-ke

river

swim

go-1PL.IMP.INCL

'Let us go to swim'.

30) nin bi-rem-ke

1PL dance-NEG-1PL.IMP. INCL

'Let us not dance'.

Similarly, Miju data for imperative/ request sentences was also collected to look into the aspect of politeness via inclusiveness in these sentences. The sentences are given below. 
$\underline{M i j u}$

31) $k i-w i$

$$
\text { atih }
$$

wan-mu

$p^{h i-\int \boldsymbol{u}}$

1SG-DAT

water

glass-QUANT

give-IMP

'(Please) Give me a glass of water'.

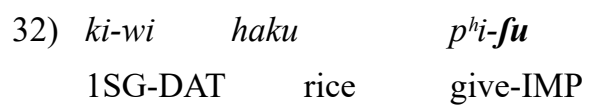

'Give me rice'.

33) ati-tanzal tai-je

water-swim go-1PL.IMP.INCL

'Let us go to swim'.

34) kam pam-je

work do-1PL.IMP.INCL

'Let us do the work'.

35) puri-je

study-1PL.IMP.INCL

'Let us study'.

The above data (25-35) were collected from speakers of both the languages and age groups (20-25, 35-40), Imperative markers are present in both Miju and Digaru (lines 25,26,27,28,31 and 32). But, importantly, no overt markers of politeness are attested in the request sentences $(25,31)$ (Note 6) which could be one of the reasons as why overt politeness markers/ strategies available in Hindi/ English (such as kripya or 'please' see 5.1) are being increasingly used by native speakers. Additionally, it is being claimed here, that when overt markers are not used (such as in 25, 31), the discursive context provide for politeness to be invoked in the hortative/ inclusive particles. In this context, Das Gupta (1977) also has not addressed any difference between imperatives and requests in Miju. His A Phrase Book in Miju, gives a good description of different types of Miju phrases (Das Gupta 1977) and his examples of imperative sentences do not provide any overt politeness strategies regarding any status, gender or age (Das Gupta, 1977, p. 28-32).

In contrast, Digaru data shows a variation in this case. It is to be noted that sentences 25) and 26) have two markers - /-na/ and /o/, whereas, sentences 27), 28) have only /-na/. The marker $/ o /$ is present only in the sentences that represents requests, otherwise all the four sentences, i.e, 25-28 are marked by a common imperative marker, i.e, /na/. The difference is possibly owing to the fact that a request sentence like 25) is unlike an English equivalent with overt marker but oblique reference (Eg: 'Can I please have a glass of water'?). The marker $/ o$ / here supports politeness reflecting a direct hortative effect because the speaker includes the listener in the action implied which corresponds to Pulu (1991)'s explanation of polite Digaru sentences. Further, /-ke/ in sentences 29) and 30) reflects the element of inclusion in hortative modality. Moreover, this element of inclusion is also reflected in Miju imperative sentences 33), 34) and 35), where /-je/ adds an inclusive sense to the imperatives with joint action of speaker and others.

Taking into account the imperatives of the mock speech and role playing conversation in Section 5.2 and elicited sentence data in Section 5.3 of both the languages, we can draw in Koller (2012)'s micro level CDA parameter: text - into our analysis. This discourse/textual analysis imparts collective identities of two distinct language groups featuring difference in structural typology. First, imperative and politeness marker with additional hortative modality are used in Digaru for such construction, whereas, only imperative marker is only used in Miju. Featured examples show that Miju do not make any distinction between imperatives and requests which is not the case for Digaru. Additionally, Digaru seems to have options of inclusive-particles like /-a/ which contextually perform politeness by including the listener in the context of action. Apart from this distinctiveness, it is important to note that both the languages also share a common feature in imperative construction. The similarity and difference is the variation in inclusive and non-inclusive options in imperative/request construction of the languages are presented in Table 1 below: 
Table 1. Difference in non-inclusive and inclusive imperatives/requests as politeness markers: Miju and Digaru

\begin{tabular}{lrr}
\hline Construction & Digaru & Miju \\
\hline Non inclusive & $-n a[+$ hort $]$ & $-f u[+$ hort $]$ \\
Inclusive & $-k e,-a$ & $-j e$ \\
\hline
\end{tabular}

Implementing Koller (2012)'s parameter on textual analysis we can say that both the language speakers use politeness features in their languages either through a hortative modality encoded in discourse particles and/or through overt inclusion markers as enumerated above. The technicality of its usage is quite different from overt use of politeness in Hindi (L2 and lingua franca) and English (official language). But, being multilingual, both Miju and Digaru speakers get into the dilemma of constructing, negotiating and changing their collective identity as speakers of minority languages in their discursive usage. Though Miju do not have parallel terms like swagatm/welcome and kripya/please, speakers appear to trigger these parallel terms in their languages within the paradigm of the functional hypothesis of Sánchez (2003, p. 11-15) (as discussed earlier) and this is done by Digaru speakers too when they do not find any appropriate words according to context.

The mock speech and conversation from the extracts I, II, III and IV suggest that the speakers from both Miju and Digaru feel this loss of speech even though they attempt to retain it in their mother language, as requested. The use of the word ' $h i$ ' to welcome, however, is a practical hypothesis for Sánchez (2003, p. 11-15). In Extract IV, we can claim that the use/activation of greeting expressions of English in the conversation is to construct a positive personal identity as well as collective identity as speakers of minority languages, acknowledging its appropriateness and importance of code-mixed greeting in the speaker's discourse rather than following the norms and values of their mother tongue and community.

\subsection{Discourse Practice of Politeness in Context: Main Findings}

The aim of the study was to see politeness strategies in use in native speakers of Miju and Digaru in various contexts, such as a) prepared formal speech b) spontaneous role playing, and c) elicited data in given imaginary contexts while implementing Koller (2012)'s parameter of macro, meso and micro level in CDA. An important factor of this context analysis is the speaker's/speakers' discourse and their role in the context. The mock context given to speakers were i) vote of thanks speech in imaginary school function (Extract I and III), ii) conversation between hotel manager and customer for booking rooms in a hotel (Extract II), and iii) conversation between two strangers where one happens to be the guest of other (Extract IV). The speakers were requested to speak in their native languages during the interview. However, in spite of this, it is seen that there is a variation in the flow of mother tongue use in the conversations. In addition, the disparity in how speech is delivered is also seen in the process. Extracts I and III are well-prepared conscious speech in which the speakers took a significant amount of time to prepare the speech (about twenty minutes each) post which they read out the speech. Notably, both speech samples were in fast speech (indicated by ' $<>$ ') as opposed to the spontaneous speech reported in Extracts II and IV (which were direct conversations between speakers in imagined contexts) which were slowly articulated. Moreover, the use of inclusive pronominal and particles performing Brown and Levinson (1978) face saving strategy (Note 7) in Extracts I and III indicate that the speakers had enough time to take these aspects into account and hence these were conscious choices on their part to include the imagined audience in the context of action.

In the mock role playing conversation, Extract II, this conscious readiness was absent on account of the speech being a spontaneous conversation expression. In this sense, while the speakers justified their conversation for not exhibiting any element of politeness asserting that the notion of superior and inferior is not present in their language community, one of the reasons for the absence of this overt element of politeness could also be the lack of cognitive readiness as also the lack of readily available discursive strategies which could be accessed spontaneously. In Extract IV too, though cognitive readiness is not there in native speaker's spontaneous speech and an overt greeting is performed by codemixing, with the use of the readily available English expression ' $h i$ '. In the discussed language setting speakers felt the need to perform a face saving strategy (Brown and Levinson,1987) and thus use the English expression hi. Digaru, notably, has the standard formulaic expression /pra je/ how are you? /are you good to greet before starting a conversation that adequately fits in this context but the use of the English term seems to have been impelled by speaker's difficulty in finding appropriate option in the spontaneous speech context hinting at an erosion of language.

Further, as mentioned above, Extract II is collected from two female speakers of age group 35-40 and Extract IV from two male speakers of age group 20-25. The age group 35-40 did not find it relevant to include politeness element in their conversation which is otherwise prominent in the age group 20-25 (Extract IV). The context and 
the role played by the speakers expects more or less similar amount of formalness in Extract II and IV. The inconsistency, it is being surmised here, is on account of a social variable concerning the speakers who were playing the roles - the speakers' age group. The gender angle is also pertinent here - with the older group women speakers preferring not to use either overt politeness markers or code-mixed greetings in spontaneous speech citing cultural considerations in contrast to younger male speakers (Extract II and IV). Here, from the patterns of language use of these two age groups, it is postulated here that the younger age group may be experiencing the limitedness in their mother tongue for maintaining a positive personal identity as well as a positive collective identity as speakers of minority communities. This justifies their tendency to activate parallel features of Hindi and English in their mother tongues (when these options are not present in their native languages) accepting their appropriateness and usefulness in discursive use even, for example, through code mixing. This cognitive awareness of limitedness can build up a sense of inferiority and insecurity in the minds of the speakers of this age group for maintaining a positive face in the society and thus instigate for language shifting.

All said, the above findings are based on limited data out of which only 32 seconds, 1 min 15 seconds, 30 seconds and 1 minute 60 seconds were analyzed for extracts I-IV. More empirical evidence is required to substantiate the initial findings reported.

\section{Summary}

The present paper makes an effort to understand the complexity of collective identity as speakers of minority languages in the context of production, perception and projection of politeness in discourse. Proposing to study the implication of collective identity in discourse practice, the research has applied the theoretical framework of Koller (2012). Her Critical Discourse Analysis' framework is based on three parameters - Macro-level (social context), Meso-level (discourse practice context, such as, production, distribution, reception, appropriation) and Micro-level (text). The study has applied these parameters and has identified some discourse features among the speakers of both the languages which invokes collective identity from the aspect of politeness which leads us to conclude:

1) Discourse markers such as politeness maker with hortative modality; inclusive pronouns and inclusive particles in imperative construction are used to present a positive collective identity in certain formal situations of interlocution (Extract I and III) where speech was prepared in advance.

2) L2 integration are noted to be used strategically by the speakers. These usages may imply a propensity to use cognitively easily available options given by languages of dominance rather than native language (Extract II and IV) in a competitive language ecology.

3) Younger speakers of both the language community seem to be cognitively aware about the limitedness of politeness discourse in their mother tongue as compared to Hindi or English and hence lapse into these dominant languages of communication in their interactions. It could also be the case that male speakers' language is witnessing this language shift in the face of endangerment. Thus the constant use of easily accessible words in the official language, which is English, and the lingua franca, which is Hindi, may have resulted in the younger and/or male speakers using less of their mother tongues, which in turn is contributing for their minority status (Extract IV).

Such an analysis clearly reflects some of the central tenets of CDA (Fairclough and Wodak, 1997, p. 277-280) that discourse constitutes society and culture; discourse does ideological work; the link between text and society is mediated and discourse is a form of social action. All said, the data presented here is limited in scope. In this line of endangered language CDA, there is sufficient scope of work to see what discursive options are present in languages and to analyze what techniques can be implemented for a good study of such competing language ecologies.

\section{Acknowledgments}

We are thankful to Dr L. David Lal (Department of HSS, IIITG) for his insightful comments regarding this paper. The data cited in this paper is part of the first author's preliminary field work in Arunachal Pradesh for research and both authors have contributed equally to the study.

\section{Lists of Abbreviations:}

$\mathrm{ABL}=$ ablative

ADV SUFF $=$ adverbial suffix

CLSFR $=$ classifier

COMP $=$ complementizer 
DAT $=$ dative

DET $=$ determiner

EXIST $=$ existential

GEN $=$ gentive

HORT $=$ hortative

IMP $=$ imperative

$\mathrm{INCL}=$ inclusive

INCL.PART $=$ inclusive particle

INFIN $=$ infinitive

INT $=$ interrogative

INTENS $=$ intensifier

$\mathrm{IP}=$ interrogative particle

LOC $=$ locative

$\mathrm{NEG}=$ negative

$\mathrm{NUM}=$ numeral

$\mathrm{OM}=$ object marker

$\mathrm{PL}=$ plural

POL.MAR $=$ politeness marker

POSS $=$ possessive

PRES $=$ present

$\mathrm{PROG}=$ progressive

$\mathrm{PST}=$ past tense

QUAN $=$ quantitative

REFL $=$ reflexive

$\mathrm{SG}=$ singular

$1=$ first person

$2=$ second person

$3=$ third person

\section{List of Symbols}

(.) micro pause, estimated, up to approximately $0.2 \mathrm{sec}$ duration

(0.4) measured pause of $0.4 \mathrm{sec}$ duration

? high rising

. low falling

, slight rising intonation

$\uparrow \quad$ small pitch up step

$\downarrow \quad$ small pitch down step

- level

(...) if parts of the original transcript are omitted when it is reproduced in a publication.

$<>$ indicate decreasing speaking rate

$><$ indicate increasing speaking rate 
$\underline{\text { WORD }}$ underline indicate emphasis

\section{References}

Adegbija, E. (2001). Saving threatened languages in Africa: A case study of Oko. In Joshua A. Fishman (Ed.), Can threatened languages be saved? Reversing language shift, revisited: A 21st century perspective, 284-308. Clevedon: Multilingual Matters. https://doi.org/10.21832/9781853597060-014

Arundale, R. B. (2010). Constituting face in conversation: Face, facework, and interactional achievement. Journal of Pragmatics, 42(8), 2078-2105. https://doi.org/10.1016/j.pragma.2009.12.021

Baker, C. (1992). Attitudes and language. Clevedon, England: Multilingual Matters.

Barua, S. (forth/2021). Politeness and language. In R.K. Agnihotri and Rajesh Kumar (Eds.) Language, mind and society: A reader. Delhi, India: Orient Blackswan.

Baruah, T. (2015). Status of endangered languages in northeast India. In G.K. Bera and K. Jose SVD (Eds.), Endangered cultures and languages in India, 82-90. Guwahati \& Delhi: Spectrum Publications.

Betholia, C. (2005). Politeness and power: An analysis of Meiteilon suffixes. Linguistics of Tibeto-Burman area, 28, 71-87. Retrieved from http://purl.org/sealang/betholia2005politeness.pdf

Blench, R. (2018, 28th February). Assessing the language situation in Arunachal Pradesh and policy for developing scripts and their use in education. Presented in Talk series in Itanagar Museum, Itanagar, Arunachal Pradesh. Retrieved

from http://www.rogerblench.info/Language/NEI/Mishmi/General/Ministry\%2028\%202\%2018.pdf

Blench, R. (2017, 8-10th February). The Mishmi languages, Idu, Tawra and Kman: A mismatch between cultural and linguistic relations. Presented in International Consortium for Eastern Himalayan Ethnolinguistic Prehistory (ICEHEP) in LaTrobe University, Melbourne, Australia. Retrieved from http://www.rogerblench.info/Language/NEI/Mishmi/MisOP/Blench\%20Mishmi\%20Melbourne\%202017.p $\mathrm{df}$

Boro, K. (2012). Serialized verbs in Boro. North east Indian linguistics, 4, 83-103. https://doi.org/10.1017/UPO9789382264521.007

Brown, N. (1837). Comparison of Indo-Chinese languages. Journal of the Asiatic society of Bengal, 6, 1023-1039. Retrieved http://pahar.in/mountains/Books\%20and\%20Articles/Indian\%20Subcontinent/1837\%20Comparison\%20of \%20Indo-Chinese\%20Languages\%20by\%20Brown\%20from\%20JASBv6pt2\%20s.pdf

Brown, P., \& Levinson, S. C. (1987). Politeness: Some universals in language usage. UK: Cambridge university press. https://doi.org/10.1017/CBO9780511813085

Choudhury, D. (2020). Multilingual education and the mother tongue: A survey of two endangered languages of Arunachal Pradesh. Language and language teaching, 8(18), 18-22. Retrieved from https://azimpremjiuniversity.edu.in/SitePages/pdf/Language-and-Language-Teaching-18-issue-july2020.pdf

Das Gupta, K. (1977). A phrase book in Miju, 28-32. Shillong/ Arunachal Pradesh: The Director of Information and Public Relations. $\quad$ Retrieved https://archive.org/details/APhraseBookInMiju/page/n35/mode/2up?q=imperative.

Dey, L. (2016). Hruso: A linguistic and cultural overview. In G. K. Bera, K. Jose, G. Lazar \& M. Antony (eds.), Endangered cultures and languages in North East India, 24-34. Guwahati \& New Delhi: Spectrum Publications.

Errington, J. (2003). Getting language rights: The rhetorics of language endangerment and loss. American anthropologist, 105(4), 723-732. https://doi.org/10.1525/aa.2003.105.4.723

Fairclough, N. (1989). Language and power. London: Longman. Retrieved from https://www.worldcat.org/title/language-and-power/oclc/17321588.

Fairclough, N. (2003). Political correctness: The politics of culture and language. Discourse \& society, 14(1), 1728. https://doi.org/10.1177/0957926503014001927

Fairclough, N. (2013). Critical discourse analysis: The critical study of language. UK \& USA: Routledge. https://doi.org/10.4324/9781315834368 
Fairclough, N., \& Wodak, R. (1997). Critical discourse analysis. In van Dijk (Ed.), Discourse studies: A multidisciplinary introduction, 2. 258-284. London: Sage. Retrieved from http://www.discourses.org/OldArticles/Critical\%20Discourse\%20Analysis.pdf

Goffman, E. (1955). On face-work: An analysis of ritual elements in social interaction. Psychiatry, 18(3), 213-231. https://doi.org/10.1080/00332747.1955.11023008

Grierson, G. A. (Ed.). (1909). Linguistic survey of India, 3. Calcutta: Superintendent of Government Printing. Retrieved from https://dsal.uchicago.edu/books/lsi/index.html

Ide, S. (1989). Formal forms and discernment: Two neglected aspects of universals of linguistic politeness. Multilingua: Journal of cross-cultural and interlanguage communication, 8(2-3), 223-248. https://doi.org/10.1515/mult.1989.8.2-3.223

Johnstone, B. (2002). Discourse analysi, 2-10. Malden, MA: Blackwell.

Kádár, D. V., \& Márquez-Reiter, R. (2015). (Im) politeness and (Im) morality: Insights from intervention. Journal of politeness research: Language, behavior, culture, 11(2), 239-260. https://doi.org/ 10.1515/pr-2015-0010

Koller, V. (2012). How to analyse collective identity in discourse-textual and contextual parameters. Critical approaches to discourse analysis across disciplines 5(2), 19-35. Retrieved from https://www.lancaster.ac.uk/fass/journals/cadaad/wp-content/uploads/2015/01/Volume-5_Koller.pdf

Koller, V. (2014). Applying social cognition research to critical discourse studies: The case of collective identities. Contemporary critical discourse studies. 149-167. London: Bloomsbury Academic. Retrieved from https://eprints.lancs.ac.uk/id/eprint/73449

Kri, H. (2008). The Mishmis. Tinsukia: The City Press.

Kroskrity, P. V. (Ed.). (2000). Regimes of language: Ideologies, polities, and identities. Santa Fe, NM: School of American Research Press. Retrieved from http://sarweb.org/index.php?sar_press_regimes_of_language

Kunda, Z. (1999). Social cognition: Making sense of people, 392. Cambridge, MA: MIT Press. https://doi.org/10.7551/mitpress/6291.001.0001

Linguistic Politeness Research Group. (Eds.). (2011). Discursive approaches to politeness. Germany: De Gruyter Mouton. https://doi.org/10.1515/9783110238679.19

Melucci, A. (1989). Nomads of the present: Social movement and identity needs in contemporary society. Philadelphia: Temple University Press, Philadelphia, PA.

Mills, S. (2009). Impoliteness in a cultural context. Journal of Pragmatics, 41(5), 1047-1060. https://doi.org/10.1016/j.pragma.2008.10.014

Mills, S. (2011). Discursive approaches to politeness and impoliteness. Discursive approaches to politeness, 1956. Germany: De Gruyter Mouton. https://doi.org/10.1515/9783110238679.19

Polletta, F., \& Jasper, J. M. (2001). Collective identity and social movements. Annual Review of Sociology, 27, 283-305. https://doi.org/10.1146/annurev.soc.27.2.283

Post, M. W., \& Burling. R. (2017). The Tibeto-Burman languages of northeast India. The Sino-Tibetan languages 2, 213-242. London \& New York: Routledge. Retrieved from https://hdl.handle.net/1959.11/21437

Pulu, J. 1991. A phrase book of Taraon language, 15-16. Itanagar, Arunachal Pradesh: Directorate of Research.

Rondo, J. (2016). Socio-cultural and religious activities of the Igu (priest) among the Idu Mishmi. In G. K. Bera, K. Jose, G. Lazar \& M. Antony (Eds.), Endangered cultures and languages in north east India, 1-23. Guwahati \& New Delhi: Spectrum Publications.

Sánchez, L. (2003). Quechua-Spanish bilingualism: Interference and convergence in functional categories. Amsterdam: John Benjamins. https://doi.org/10.1075/lald.35

Snow, D. (2001). Collective identity and expressive forms. Center for the study of democracy. California Digital Library. https://doi.org/10.1016/B0-08-043076-7/04094-8

Tajfel, H. (1974). Social identity and intergroup behaviour. Social science information, 13 (2), 65-93. https://doi.org/10.1177/053901847401300204

Terkourafi, M. (2001). Politeness in Cypriot Greek: A frame-based approach. Doctoral dissertation. University of Cambridge. Retrieved from http://hdl.handle.net/2142/9573

van Dijk, T. A. (1993). Principles of critical discourse analysis. Discourse \& society, 4(2), 249-283. 
https://doi.org/10.1177/0957926593004002006

van Dijk T.A. (2003). The Discourse-knowledge interface. In Weiss G., Wodak R. (Eds.) Critical discourse analysis, 85-109. London: Palgrave Macmillan. https://doi.org/10.1057/9780230514560_5

van Dijk, T. A. (2008). Discourse and power. New York: Palgrave Macmillan. https://doi.org/10.1007/978-1-13707299-3

van Dijk, T. A. (2009a). Society and discourse: How social contexts influence text and talk. Cambridge, New York: Cambridge University Press. https://doi.org/10.1017/CBO9780511575273

van Dijk, T. A. (2009b). Critical discourse studies: A socio-cognitive approach. Methods of critical discourse analysis, 2(1), 62-86. $\quad$ Retrieved from $\mathrm{http}: / /$ www.discourses.org/OldArticles/Critical\%20Discourse\%20Studies.pdf

van Dijk, T. A. (2014). Discourse and knowledge: A socio-cognitive approach. Cambridge: Cambridge University Press. https://doi.org/10.1017/CBO9781107775404

Weiss, G., \& Wodak, R. (Eds.). (2007). Critical discourse analysis. New York: Palgrave Macmillan.

Wendel, J., \& Heinrich, P. (2012). A framework for language endangerment dynamics: The effects of contact and social change on language ecologies and language diversity. International journal of the sociology of language, 2012 (218), 145-166. https://doi.org/10.1515/ijsl-2012-0062

Wodak, R. (2002). Aspects of critical discourse analysis. Zeitschrift für Angewandte Linguistik, 36(10), 5-31. Retrieved from https://www.research.lancs.ac.uk/portal/en/publications/aspects-of-critical-discourseanalysis(21c41cb5-af51-41cb-a427-8188a89c7991).html

\section{Notes}

Note 1. The use of different names to identify both languages is illustrated in Brown (1837), Grierson (1909) and Kri (2008). The names of the varieties as enumerated here are those which are most widely used.

Note 2. In-group is a social group to which an individual identifies as a member, based on ethnocentrism and outgroup is one with which an individual does not psychologically identify as a member (Tajfel, 1974).

Note 3. First author field notes.

Note 4. First author field notes.

Note 5. Negative face is the desire not to be imposed upon, intruded, or otherwise put upon Brown and Levinson (1987).

Note 6. The interviewer, while eliciting the data, had specifically used the overt politeness marker (English 'Please') for sentences 25 and 31 which did not have a parallel term in either Digaru or Miju. However, pertinently, the marker /-fu/ is used for both imperative and request sentence 31) and 32) in Miju.

Note 7. Four key forms of politeness techniques are outlined by Brown and Levinson: bald on-record, negative politeness, positive politeness, and off-record (indirect), as well as actually not using the act that attacks the face (Brown and Levinson, 1987).

\section{Copyrights}

Copyright for this article is retained by the author(s), with first publication rights granted to the journal.

This is an open-access article distributed under the terms and conditions of the Creative Commons Attribution license (http://creativecommons.org/licenses/by/4.0/). 